\title{
Comparative expression profiles of host circulating miRNAs in response to Trichinella spiralis infection
}

\author{
Xiao Han Ma ${ }^{1,2+}$, Hui Jun Ren ${ }^{1,2^{*}+}$, Ruo Yu Peng ${ }^{1,2}$, Yi Li $^{1,2}$ and Liang Ming ${ }^{1,2^{*}}$
}

\begin{abstract}
Trichinellosis is an important food-borne parasitic zoonosis throughout the world. At present, the mechanisms of Trichinella spiralis infection remain unclear. Acquiring detailed information on the host-Trichinella interaction would be beneficial for the development of new strategies for trichinellosis control. Circulating miRNAs are stably detectable in the blood of humans and animals infected with parasites. Circulating miRNAs might regulate the expression of target genes in pathological responses during infection and might be novel potential biomarkers of parasitic diseases. In the present study, a total of ten differentially expressed circulating mouse miRNAs with $\mid \log _{2}$ (fold change) $\mid \geq 1.0$ and FDR $<0.01$ were found during T. spiralis infection, of which five were upregulated and five were downregulated. GO and KEGG analyses showed that the target genes of the ten miRNAs were enriched in many signalling pathways, especially focal adhesion, MAPK pathway, and so on. The results of qRT-PCR showed that among the five upregulated miRNAs, mmu-miR-467a-3p and mmu-miR-467d-3p expression in mouse serum reached a peak at 30 days postinfection (dpi). The expression of mmu-miR-376b-3p and mmu-miR-664-3p increased significantly at $18 \mathrm{dpi}$ and then decreased at $30 \mathrm{dpi}$. The expression of mmu-miR-292a-5p gradually decreased from 12 to $30 \mathrm{dpi}$. Among the $5 \mathrm{down}$ regulated miRNAs, mmu-miR-199a-5p expression was significantly downregulated at $30 \mathrm{dpi}$, while the expression levels of the other four miRNAs (mmu-miR-455-5p, mmu-miR-125b-5p, mmu-miR-125a-5p, and mmu-miR-615-3p) were significantly lower compared with the control, showing a steady downregulation at different phases of infection. These findings will help to further understand the host-Trichinella interaction and provide promising serum biomarkers for trichinellosis.
\end{abstract}

\section{Introduction}

Trichinellosis is an important food-borne parasitic zoonosis caused by the consumption of raw or undercooked meat containing Trichinella spiralis infective larvae. T. spiralis can infect a range of animal species, including humans. Human trichinellosis is distributed in 55 countries and is considered an emerging or re-emerging disease [1]. Muscle larvae are released from their capsules

\footnotetext{
*Correspondence: huijunren@126.com; mingliang_2015@sina.com

${ }^{\dagger}$ Xiao Han Ma and Hui Jun Ren are co-first authors on this work

${ }^{1}$ Department of Clinical Laboratory, The First Affiliated Hospital of Zhengzhou University, Zhengzhou 450052, China

Full list of author information is available at the end of the article
}

after ingestion in the host stomach and then activated into intestinal infective larvae at $0.9 \mathrm{~h}$ post-infection (hpi). The infective larvae penetrate into the host intestinal epithelium, where they undergo four moults and mature to adult worms at 30-40 hpi [2]. Female worms produce newborn larvae at 5 days post-infection (dpi), which then penetrate the intestinal epithelium and enter the blood and lymphatic system. These larvae reach the host striated muscle tissue, resulting in the formation of nurse cells at $26 \mathrm{dpi}$, where the larvae can survive for years [2]. Considering the whole life cycle, it can be seen that entry into host blood circulation and invasion of muscle cells are crucial points for T. spiralis infection. Interactions between $T$. spiralis and the host determine

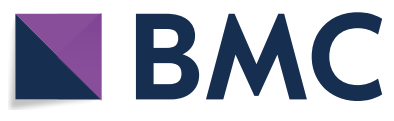

c) The Author(s) 2020. This article is licensed under a Creative Commons Attribution 4.0 International License, which permits use, sharing, adaptation, distribution and reproduction in any medium or format, as long as you give appropriate credit to the original author(s) and the source, provide a link to the Creative Commons licence, and indicate if changes were made. The images or other third party material in this article are included in the article's Creative Commons licence, unless indicated otherwise in a credit line to the material. If material is not included in the article's Creative Commons licence and your intended use is not permitted by statutory regulation or exceeds the permitted use, you will need to obtain permission directly from the copyright holder. To view a copy of this licence, visit http://creativeco mmons.org/licenses/by/4.0/. The Creative Commons Public Domain Dedication waiver (http://creativecommons.org/publicdomain/ zero/1.0/) applies to the data made available in this article, unless otherwise stated in a credit line to the data. 
whether its infection is established in the host and the degree of clinical symptoms.

microRNAs (miRNAs) are a class of highly conserved (21-23 nucleotides long), endogenous, noncoding RNAs. They participate in physiological and pathological processes by regulating gene expression, such as inflammatory reactions, immune responses, and tumour occurrence [3]. Previous studies have shown that host miRNAs in relevant tissues or cells are dysregulated during infection with parasites, indicating their crucial roles in host responses to pathogen challenge. Functional analyses have shown that some host dysregulated miRNAs, such as miR-20b, are involved in host immune responses against parasitic infection [4]. Moreover, host miRNAs have been demonstrated to alter the host-parasite interaction and thus further influence the infection and development of the parasites $[5,6]$. Recent studies found that circulating miRNAs were stably detectable in the blood or body fluids of humans and animals with parasite infection $[7,8]$. Hence, they could not only be regarded as key mediators of the host-parasite interaction but could also prove to be potentially useful as novel biomarkers for parasite infection. For instance, miR-233 in the blood serum of mice infected with Schistosoma japonicum was significantly upregulated and returned to near normal levels after praziquantel treatment, implying that miR-233 may be a potential biomarker for Schistosoma infection [9]. Since parasite-specific antibodies cannot be detected during the early stage of infection, there are few biomarkers with high sensitivity and high specificity for early infection. Identification of circulating miRNAs of hosts infected with parasites will provide new approaches for biomarkers of early infection.

T. spiralis species-associated miRNAs have recently been identified by Solexa deep sequencing and biological analyses [10], providing a possibility to better understand their roles in the establishment of infection, growth and development, and host-Trichinella interactions [11]. However, host circulating miRNAs associated with T. spiralis infection have not been profiled yet. In the present study, ten host circulating miRNAs were dysregulated during T. spiralis infection. KEGG analysis showed that several of them participate in the MAPK signalling pathway, Focal adhesion, and so on. These findings will help us to further understand the host-Trichinella interaction and identify highly effective and specific biomarkers and prophylactic vaccines.

\section{Materials and methods Ethics statement}

All animal experiments in this study were employed in strict accordance with the Animal Ethics Procedures and Guidelines (People's Republic of China). All animal experimental procedures reported herein were approved by the Ethics Committee of Scientific Research and Clinical Trial of the First Affiliated Hospital of Zhengzhou University (Permit No.: 2019-KY-267).

\section{Parasites and animals}

In this study, the T. spiralis isolate strain ISS534 was obtained from a domestic pig in Nanyang city of Henan Province, China. The isolate was maintained in Kunming female mice. Specific pathogen-free BALB/c mice were obtained from the Experimental Animal Center of Henan Province. These mice were provided access to distilled water and sterilized food.

\section{Collection of mouse serum post-infection}

T. spiralis muscle larvae were obtained from muscles of Kunming mice using standard pepsin/hydrochloric acid artificial digestion [12]. Sixty BALB/c mice (6-8 weeks old) were randomly and equally divided into two groups. Each mouse in the experimental group (E) was orally inoculated with approximately 500 muscle larvae. At the same time, mice inoculated with saline solution were used as the control (C). Whole blood was drawn from the orbital sinus of each mouse at $30 \mathrm{dpi}$. The blood samples were allowed to stand at $4{ }^{\circ} \mathrm{C}$ for $1 \mathrm{~h}$, and serum (approximately $200 \mu \mathrm{L}$ ) from each mouse was separated by centrifugation at $3500 \times g$ for $10 \mathrm{~min}$ at $4{ }^{\circ} \mathrm{C}$. The serum of ten mice in each group was randomly pooled as one biological replicate, and each group had three biological replicates. Serum samples were stored at $-80{ }^{\circ} \mathrm{C}$ to be utilized for RNA extraction.

\section{Small RNA sequencing}

Total RNA was extracted from serum samples using RNAiso Blood reagent (Takara) according to the manufacturer's instructions. Total RNA purity and concentration were estimated using a Nanodrop 2000 (Thermo Fisher Scientific, USA) at $260 \mathrm{~nm}$ and $280 \mathrm{~nm}$. RNA fragments were separated using polyacrylamide gel electrophoresis (PAGE), and small RNAs with lengths of 18-30 nt were recovered. Then, $3^{\prime}$ and $5^{\prime}$ adaptors were ligated to the ends of recovered small RNAs as PCR primers. The cDNAs were obtained and amplified by reverse transcription PCR. The PCR products were purified using PAGE and then dissolved in EB solution to generate the sequencing libraries. The yield and quality of the libraries were evaluated using an Agilent 2100 Bioanalyzer and the StepOnePlus ${ }^{\text {TM }}$ Real-Time PCR System (ABI). The cDNA libraries were sequenced by the HiSeq 2000 platform (Illumina, USA), and raw reads were generated. 


\section{Analysis of sequencing data}

Raw reads obtained by HiSeq sequencing were filtered through the following steps: (1) removing low-quality reads; (2) removing $\mathrm{N}$ reads with proportions greater than $10 \%$ ( $\mathrm{N}$ means unable to determine the base information); and (3) removing reads with $5^{\prime}$ primer contaminants, reads with poly A, reads without $3^{\prime}$ primer or the insert fragments, and reads shorter than $18 \mathrm{nt}$. Then, clean reads were analysed for their sequence types, sequence number, and length distribution. The clean reads were mapped to the reference mouse genome (NCBI: GCA_000001635.8) using SOAP and Bowtie software without any mismatch to remove contaminant reads from the Trichinella transcriptome. Reads of rRNA, scRNA, snoRNA, snRNA, and tRNA were removed by mapping clean reads to the GenBank database [13] and Rfam [14]. The remaining reads were mapped to the miRBase v21.0 database [15] to obtain known miRNAs. The novel miRNAs were identified by using miRDeep2 software as described previously [16].

\section{Analysis of differentially expressed miRNAs}

To identify the differentially expressed circulating miRNAs in mice infected with $T$. spiralis, the expression of miRNAs in each library was normalized to the number of transcripts per million (TPM) [17], and differential expression analysis between the $\mathrm{E}$ and $\mathrm{C}$ groups was performed using Student's $t$ test. $P$ values were adjusted using the Benjamini \& Hochberg method, and a corrected $P$ value (FDR) of 0.01 was considered statistically significant. Then, the normalized expression values were used to calculate the fold change of each miRNA in the two groups using the formula fold changes = experimental group/control group. The miRNAs with $\mid \log _{2}$ (fold change) $\mid \geq 1.0$ and FDR $<0.01$ were defined as differentially expressed between the two groups.

\section{qRT-PCR analysis of differentially expressed miRNAs}

To further validate the sequencing results, all ten differentially expressed miRNAs (mmu-miR-467a-3p, mmumiR-467d-3p, mmu-miR-292a-5p, mmu-miR-376b-3p, mmu-miR-664-3p, mmu-miR-455-5p, mmu-miR125b-5p, mmu-miR-125a-5p, mmu-miR-615-3p, and mmu-miR-199a-5p) were detected in mouse serum at 30 dpi using qRT-PCR. The specific stem-loop RT primers for each miRNA were designed using Primer 5.0 software (Table 1). The U6 snRNA was used as a reference gene to normalize gene expression. A total of $180 \mathrm{BALB} / \mathrm{c}$ mice were randomly and equally divided into the $\mathrm{E}$ and $\mathrm{C}$ groups. Each mouse in the E group ( 90 mice) was orally inoculated with approximately $500 \mathrm{ML}$, and in the $\mathrm{C}$ group, the mice were inoculated with saline solution. At $30 \mathrm{dpi}$, the mice were subjected to serum collection via orbital sinus bleeding, and then they were sacrificed. The pooled serum from ten mice was used as one sample, and thus, every group had 9 mixed serum samples. Total RNA was extracted from each serum sample using RNAiso Blood reagent (Takara) and was reverse-transcribed

Table 1 Primers used for qRT-PCR to determine miRNA expression

\begin{tabular}{|c|c|c|c|}
\hline Name & MiRNA sequence & RT primer $5^{\prime}-3^{\prime}$ & QRT-PCR F primer $5^{\prime}-3^{\prime}$ \\
\hline mmu-miR-467a-3p & CAUAUACAUACACACACCUACA & $\begin{array}{l}\text { GTCGTATCCAGTGCAGGGTCCGAGGTATTCGCACTGGATACG } \\
\text { ACTGTAGG }\end{array}$ & GCGCGCATATACATACACACA \\
\hline mmu-miR-467d-3p & AUAUACAUACACACACCUACAC & $\begin{array}{l}\text { GTCGTATCCAGTGCAGGGTCCGAGGTATTCGCACTGGATACG } \\
\text { ACGTGTAG }\end{array}$ & CGCGCGATATACATACACACAC \\
\hline mmu-miR-292a-5p & ACUCAAACUGGGGGCUCUUUUG & $\begin{array}{l}\text { GTCGTATCCAGTGCAGGGTCCGAGGTATTCGCACTGGATACG } \\
\text { ACCAAAAG }\end{array}$ & GCGACTCAA \\
\hline mmu-miR-376b-3p & AUCAUAGAGGAACAUCCACUU & $\begin{array}{l}\text { GTCGTATCCAGTGCAGGGTCCGAGGTATTCGCACTGGATACG } \\
\text { ACAAGTGG }\end{array}$ & GAACAT \\
\hline mmu-miR-664-3p & UAUUCAUUUACUCCCCAGCCUA & $\begin{array}{l}\text { GTCGTATCCAGTGCAGGGTCCGAGGTATTCGCACTGGATACG } \\
\text { ACTAGGCT }\end{array}$ & GCGCGTATTCATTTACTCCCC \\
\hline mmu-miR-455-5p & UAUGUGCCUUUGGACUACAUCG & $\begin{array}{l}\text { GTCGTATCCAGTGCAGGGTCCGAGGTATTCGCACTGGATACG } \\
\text { ACCGATGT }\end{array}$ & CGCGTATGTGCCTTTGGACT \\
\hline mmu-miR-125b-5p & UCCCUGAGACCCUAACUUGUGA & $\begin{array}{l}\text { GTCGTATCCAGTGCAGGGTCCGAGGTATTCGCACTGGATACG } \\
\text { ACTCACAA }\end{array}$ & CGCGTCCCTGAGACCCTAAC \\
\hline mmu-miR-125a-5p & UCCCUGAGACCCUUUAACCUGUGA & $\begin{array}{l}\text { GTCGTATCCAGTGCAGGGTCCGAGGTATTCGCACTGGATACG } \\
\text { ACTCACAG }\end{array}$ & GCGTCCCTGAGACCCTTTAAC \\
\hline mmu-miR-615-3p & UCCGAGCCUGGGUCUCCCUCUU & $\begin{array}{l}\text { GTCGTATCCAGTGCAGGGTCCGAGGTATTCGCACTGGATACG } \\
\text { ACAAGAGG }\end{array}$ & CGTCCGAGCCTGGGTCTC \\
\hline mmu-miR-199a-5p & CCCAGUGUUCAGACUACCUGUUC & $\begin{array}{l}\text { GTCGTATCCAGTGCAGGGTCCGAGGTATTCGCACTGGATACG } \\
\text { ACGAACAG }\end{array}$ & CGCGCCCAGTGTTCAGACTAC \\
\hline
\end{tabular}


using PrimeScript RT reagent Kit with gDNA Eraser (Takara). qRT-PCR was performed using TB Green Premix Ex Ta II (Takara). The PCRs in total volume of $10 \mu \mathrm{L}$ were analysed on Roche LightCycler ${ }^{\circledR} 480$ II with the following cycling parameters: 1 cycle at $95{ }^{\circ} \mathrm{C}$ for $30 \mathrm{~s}$, followed by 40 cycles of amplification at $95{ }^{\circ} \mathrm{C}$ for $5 \mathrm{~s}$ and $60{ }^{\circ} \mathrm{C}$ for $30 \mathrm{~s}$. Relative expression levels of miRNAs were normalized to U6 levels and calculated using the $2^{-\Delta \Delta \mathrm{Ct}}$ method [18]. The results are shown as the mean \pm SD. For qRT-PCR, each sample was analysed in technical triplicates.

Moreover, the expression changes of these miRNAs were also analysed at 12 and 18 dpi using qRT-PCR. At every time point, every group ( $\mathrm{E}$ or $\mathrm{C}$ group) had 9 mixed serum samples. The method of serum collection was the same as that at $30 \mathrm{dpi}$. Then, the serum samples were used to evaluate the relative expression of these miRNAs at 12 and $18 \mathrm{dpi}$.

\section{miRNA target prediction and function analysis}

Target genes of miRNAs were identified using the four prediction programmes TargetScan [19], miRanda [20], PITA [21], and RNAhybrid [22], and only miRNA target genes from the common predicted results were considered for further analysis. Target genes of the differentially expressed miRNAs were used in Gene Ontology (GO) and Kyoto Encyclopedia of Genes and Genomes (KEGG) pathway enrichment analyses using the DAVID database [23]. The $P$ value was calculated based on Fisher's exact test, and $P<0.05$ was considered significant [23].

\section{Results}

Characteristics of small RNA sequencing

In the present study, the differentially expressed miRNAs in the blood serum of mice infected with T. spiralis at $30 \mathrm{dpi}$ were compared with those in uninfected mice. The workflow of this study is shown in Figure 1.

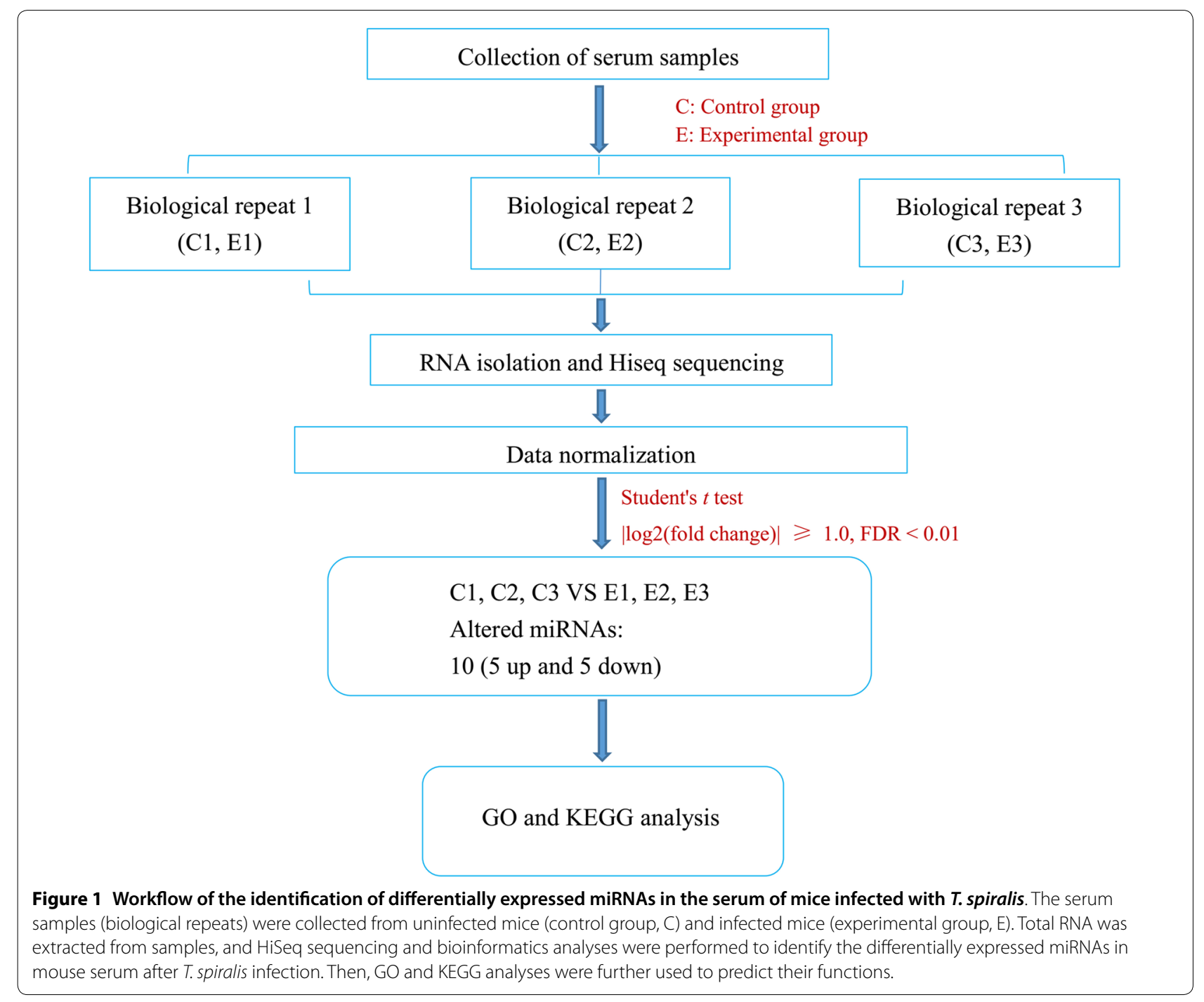


After removing low-quality reads and linker sequences, high-quality clean reads of six libraries were obtained, as shown in Additional file 1. The length of small RNAs mainly ranged from 21 to 23 nt (Figure 2), which was consistent with miRNA length. Small RNAs of the six libraries were annotated after mapping to the GenBank database and Rfam of T. spiralis. In addition to miRNAs, other small RNAs, including rRNAs, scRNAs, snoRNAs, snRNAs, and tRNAs, were also detected, as shown in Additional file 2. After alignment to the miRBase (version 21.0) database, known miRNAs were then obtained for further analysis (see Additional file 3). In addition, novel miRNAs were identified, and their sequences are displayed in Additional file 4. The secondary structures of novel miRNA precursors were predicted, several of which are shown in Figure 3.

\section{Differentially expressed circulating miRNAs of mice infected with $T$. spiralis}

To investigate expression changes of host miRNAs after T. spiralis infection, mouse miRNAs in the infected sera were compared with those of the controls. The expression levels of miRNAs in the T. spiralis-infected group (three biological repeats) were normalized, and the same analysis was applied to the control group. The relative expression levels of miRNAs are shown in Additional file 5. Subsequently, miRNAs with $\mid \log _{2}$ (fold change) $\mid \geq 1.0$ and FDR $<0.01$ were considered differentially expressed. The results showed that ten differentially expressed known miRNAs were found in the infected mouse sera. Among them, 5 miRNAs (mmu-miR467a-3p, mmu-miR-467d-3p, mmu-miR-292a-5p, mmumiR-376b-3p, and mmu-miR-664-3p) were upregulated and 5 miRNAs (mmu-miR-455-5p, mmu-miR-125b-5p, mmu-miR-125a-5p, mmu-miR-615-3p, and mmu-miR199a-5p) were significantly downregulated (Table 2). No differentially expressed novel miRNAs were identified. Cluster analysis was performed to investigate the expression patterns of all the altered miRNAs based on the $\mid \log _{2}$ (E/C) $\mid$ and $P$ value.

\section{Verification of differentially expressed miRNAs by qRT-PCR}

To further verify the sequencing data, all ten differentially expressed miRNAs were analysed by qRT-PCR. The expression trends obtained for the altered miRNAs were consistent with the original HiSeq sequencing results. There was an increase in the expression of mmu-miR467a-3p, mmu-miR-467d-3p, mmu-miR-292a-5p, mmumiR-376b-3p and mmu-miR-664-3p and a reduction in the expression of mmu-miR-455-5p, mmu-miR-125b-5p,

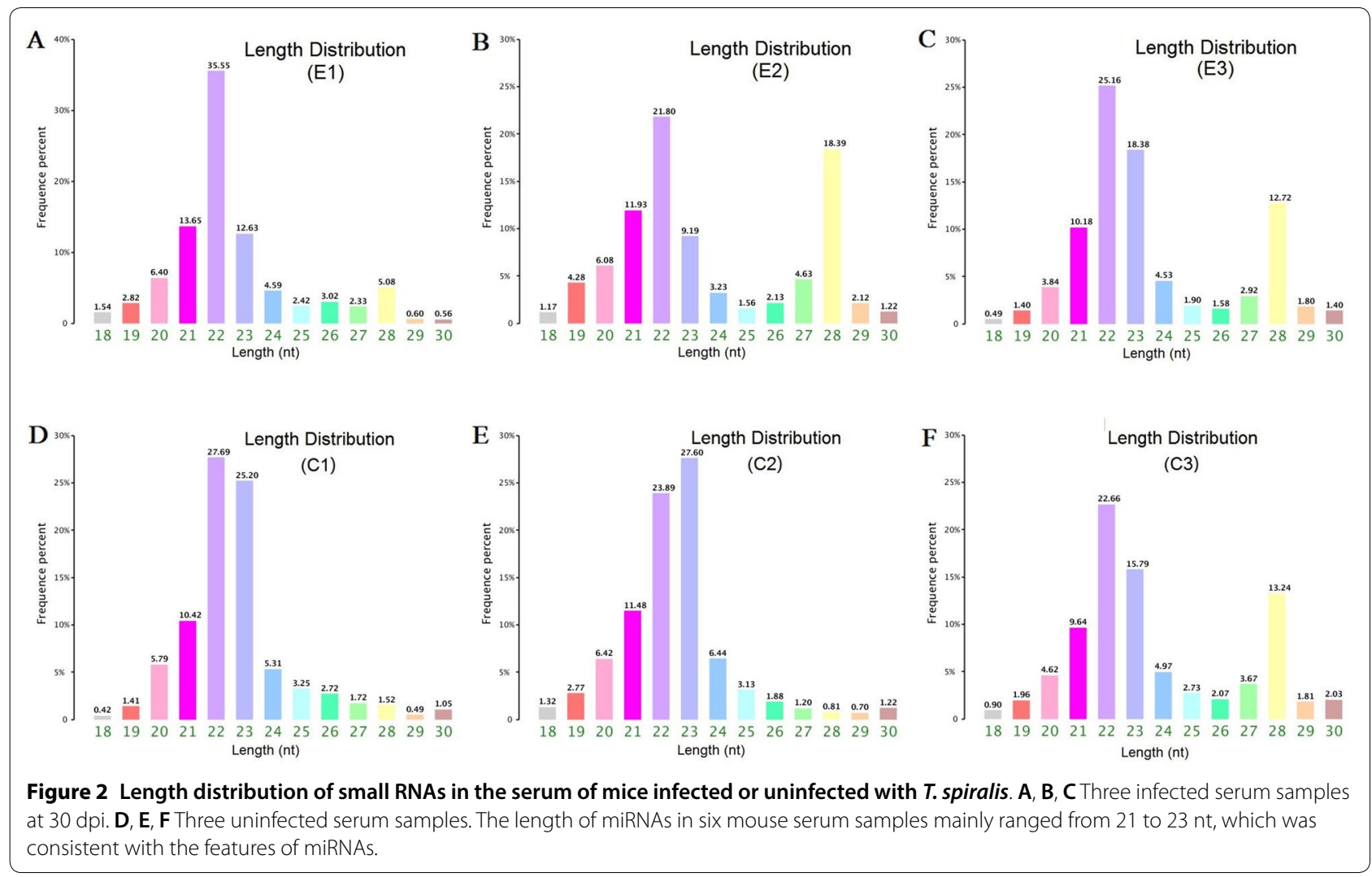




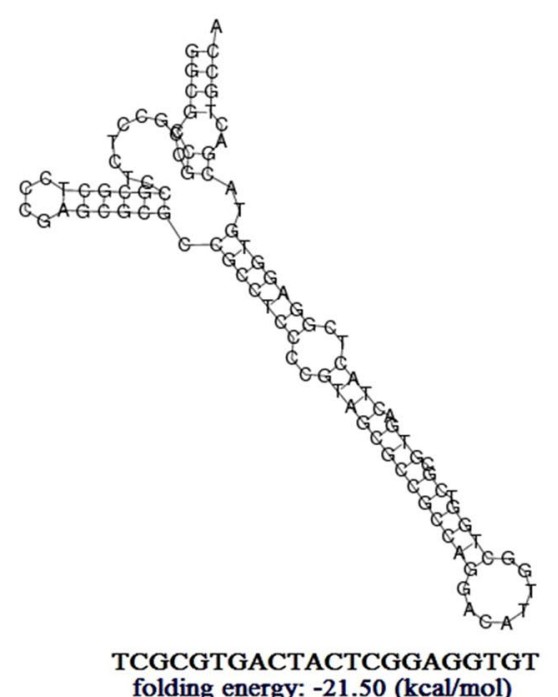

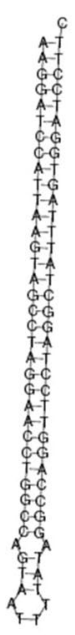

TAAGTAGCCTAGGAACCTGG folding energy: $-61.60(\mathrm{kcal} / \mathrm{mol})$

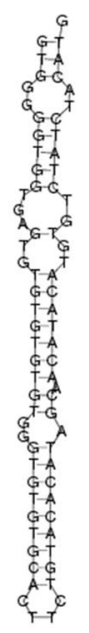

TGAGTGTGTGTGTGTGGGTGT folding energy: $-32.30(\mathrm{kcal} / \mathrm{mol})$

Figure 3 The secondary structures of several predicted novel miRNA precursors and the corresponding mature sequences.

mmu-miR-125a-5p, mmu-miR-615-3p, and mmu-miR$199 \mathrm{a}-5 \mathrm{p}$ in the serum of mice infected with T. spiralis (Figure 4).

\section{Prediction of miRNA target genes and functional enrichment}

To gain insights into the possible functions of differentially expressed circulating miRNAs in mice infected with T. spiralis, their target genes were predicted using RNAhybrid, miRanda, TargetScan, and PITA. The predicted target genes common to all four databases were considered the final miRNA target genes (Additional file 6). The number of target genes for each miRNA was 4140 for mmu-miR-125a-5p, 3092 for mmu-miR125b-5p, 2626 for mmu-miR-199a-5p, 766 for mmumiR-455-5p, 3392 for mmu-miR-615-3p, 522 for mmu-miR-467a-3p, 387 for mmu-miR-467d-3p, 1329 for mmu-miR-292a-5p, 191 for mmu-miR-376b-3p, and 156 for mmu-miR-664-3p. Then, the miRNA target genes were further functionally categorized into biological process (BP), molecular function (MF), and cellular component (CC) according to GO analysis (Table 2, Additional file 7). GO enrichment analysis revealed that in the BP category, the upregulated miRNAs were mainly involved in "protein phosphorylation", "transcription, DNAtemplated", "cell differentiation", "multicellular organism development", and "cell-cell adhesion" (Figure 5A). With regard to the downregulated miRNAs, "cell adhesion", "cell differentiation", "protein transport", "apoptotic process", and "immune system process" were some of the most frequent GO terms (Figure 5B). KEGG pathway and enrichment analysis revealed that target genes of the differentially expressed miRNAs were involved in 297 different pathways. The enriched pathways for each miRNA are shown in Additional file 8, and part of the enriched pathways are shown in Figure 6. Target genes were mostly enriched in Focal adhesion (Figure 7), MAPK signalling pathway, Carbohydrate digestion and absorption, ECMreceptor interaction, HTLV-I infection, mTOR signalling pathway, Progesterone-mediated oocyte maturation, ErbB signalling pathway, and $\mathrm{T}$ cell receptor signalling pathway.

\section{Expression levels of the altered circulating miRNAs at different phases of infection}

To observe the variation in expression levels of the altered circulating miRNAs during infection, the infected sera were collected at 12,18 , and $30 \mathrm{dpi}$. The ten differentially expressed miRNAs in these serum samples were analysed by qRT-PCR. As shown in Figure 8, among the 5 upregulated miRNAs, mmu-miR-467a-3p and mmumiR-467d-3p expression gradually increased from 12 to $30 \mathrm{dpi}$. The expression of mmu-miR-376b-3p and mmu-miR-664-3p increased significantly at $18 \mathrm{dpi}$ and then decreased at $30 \mathrm{dpi}$. In addition, the expression of mmu-miR-292a-5p gradually decreased from 12 to 30 dpi. Among the 5 downregulated miRNAs, mmu-miR199a-5p expression was significantly downregulated at 30 dpi. Interestingly, the expression levels of the other four miRNAs (mmu-miR-455-5p, mmu-miR-125b-5p, mmumiR-125a-5p, and mmu-miR-615-3p) were significantly lower than those in the control group, showing a steady downregulation at different phases of infection. 
Table 2 A subset of putative target genes and GO terms of altered host circulating miRNAs after T. spiralis infection

\begin{tabular}{|c|c|c|c|c|c|}
\hline Name & Length & $\log _{2}$ (fold change) & FDR & GO term & Target gene \\
\hline \multirow[t]{4}{*}{$\operatorname{miR}-467 a-3 p$} & 22 & 11.99 & 0.005113502 & GO:0005515 protein binding & Zinc finger protein 516 (Zfp516) \\
\hline & & & & GO:0046872 metal ion binding & Nuclear factor of activated T cells \\
\hline & & & & GO:0005178 integrin binding & $\begin{array}{l}\text { Cytoplasmic, calcineurin dependent } 2 \\
\text { (Nfatc2) }\end{array}$ \\
\hline & & & & GO:0016881 acid-amino acid ligase activity & $\begin{array}{l}\text { TGF-beta activated kinase 1/MAP3K7 binding } \\
\text { protein } 3 \text { (Tab 3) }\end{array}$ \\
\hline $\operatorname{miR}-467 d-3 p$ & 22 & 11.99 & 0.0051135 & $\begin{array}{l}\text { GO:0005515 protein binding } \\
\text { GO:0008134 transcription factor binding } \\
\text { GO:0005178 integrin binding } \\
\text { GO:0016881 acid-amino acid ligase activity }\end{array}$ & $\begin{array}{l}\text { Vascular endothelial growth factor A (Vegfa) } \\
\text { activating transcription factor } 2 \text { (Atf2) } \\
\text { transcription factor } 3 \text { (Tcf3) }\end{array}$ \\
\hline \multirow[t]{4}{*}{ miR-292a-5p } & 22 & 5.78 & $1.55 E-07$ & GO:0008092 cytoskeletal protein binding & Cadherin-related family member 1 (Cdhr1) \\
\hline & & & & GO:0019899 enzyme binding & $\begin{array}{l}\text { Mast cell immunoglobulin like receptor } 1 \\
\text { (Milr1) }\end{array}$ \\
\hline & & & & GO:0005515 protein binding & Tight junction protein 3 (Tjp3) \\
\hline & & & & GO:0008168 methyltransferase activity & $\begin{array}{l}\text { Protein kinase C and casein kinase substrate } \\
\text { in neurons } 3 \text { (Pacsin3) }\end{array}$ \\
\hline \multirow[t]{4}{*}{$\operatorname{miR}-376 b-3 p$} & 21 & 5.05 & 0.009988095 & GO:0004672 protein kinase activity & Laminin, alpha 5 (Lama5) \\
\hline & & & & GO:0016740 transferase activity & Dual specificity phosphatase 22 (Dusp22) \\
\hline & & & & GO:0042802 identical protein binding & $\begin{array}{l}\text { Membrane associated tyrosine/threonine } 1 \\
\text { (Pkmyt1) protein kinase }\end{array}$ \\
\hline & & & & GO:0005216 ion channel activity & $\begin{array}{l}\text { calcium/calmodulin-dependent protein } \\
\text { kinase IV (Camk4) }\end{array}$ \\
\hline \multirow[t]{2}{*}{$\operatorname{miR}-664-3 p$} & 22 & 3.56 & 0.005113502 & $\begin{array}{l}\text { GO:0005229 intracellular calcium activated } \\
\text { chloride channel activity }\end{array}$ & Protein kinase C substrate 80 K-H (Prkcsh) \\
\hline & & & & $\begin{array}{l}\text { GO:0008237 metallopeptidase activity } \\
\text { GO:0005509 calcium ion binding }\end{array}$ & \\
\hline \multirow[t]{5}{*}{$\operatorname{miR}-455-5 p$} & 22 & -3.04 & 0.009449003 & GO:0042605 peptide antigen binding & Calponin 2 (Cnn2) \\
\hline & & & & GO:0030881 beta-2-microglobulin binding & Phosphatase and actin regulator 1 (Phactr1) \\
\hline & & & & GO:0042608 T cell receptor binding & Protein kinase C, beta (Prkcb) \\
\hline & & & & $\begin{array}{l}\text { GO:0004674 protein serine/threonine } \\
\text { kinase activity }\end{array}$ & Alpha-kinase 1 (Alpk1) \\
\hline & & & & GO:0008235 metalloexopeptidase activity & \\
\hline \multirow[t]{4}{*}{$\operatorname{miR}-125 b-5 p$} & 22 & -3.11 & 0.005545304 & GO:0005515 protein binding & Tight junction associated protein 1 (Tjap1) \\
\hline & & & & GO:0004672 protein kinase activity & Interferon regulatory factor 1 (Irf1) \\
\hline & & & & GO:0016740 transferase activity & $\begin{array}{l}\text { Chemokine (C-C motif) receptor } 8 \text { (Ccr8); } \\
\text { CD247 antigen }(\mathrm{Cd} 247)\end{array}$ \\
\hline & & & & GO:0004222 metalloendopeptidase activity & $\begin{array}{l}\text { MAP/microtubule affinity regulating kinase } \\
2 \text { (Mark2) }\end{array}$ \\
\hline \multirow[t]{4}{*}{$\operatorname{miR}-125 a-5 p$} & 24 & -3.21 & 0.005113502 & GO:0005515 protein binding & $\begin{array}{l}\text { Tubulin, gamma complex associated protein } \\
6 \text { (Tubgcp6) }\end{array}$ \\
\hline & & & & GO:0003779 actin binding & Interleukin 6 signal transducer (II6st) \\
\hline & & & & $\begin{array}{l}\text { GO:0004674 protein serine/threonine } \\
\text { kinase activity }\end{array}$ & Protein kinase C, zeta (Prkcz) \\
\hline & & & & GO:0008237 metallopeptidase activity & Chemokine (C-C motif) receptor 9 (Ccr9) \\
\hline $\operatorname{miR}-615-3 p$ & 22 & -3.369881789 & 0.005545304 & $\begin{array}{l}\text { GO:0005515 protein binding } \\
\text { GO:0004712 protein serine/threonine/ } \\
\text { tyrosine kinase activity } \\
\text { GO:0008092 cytoskeletal protein binding } \\
\text { GO:0016787 hydrolase activity }\end{array}$ & $\begin{array}{l}\text { Zinc finger protein } 592 \text { (Zfp592) } \\
\text { CD40 antigen (Cd40) } \\
\text { Dual specificity Phosphatase } 6 \text { (Dusp6) } \\
\text { Dynamin binding protein (Dnmbp) }\end{array}$ \\
\hline miR-199a-5p & 23 & -3.557273923 & 0.003171509 & $\begin{array}{l}\text { GO:0019901 protein kinase binding } \\
\text { GO:0050839 cell adhesion molecule bind- } \\
\text { ing } \\
\text { GO:0051011 microtubule minus-end } \\
\text { binding } \\
\text { GO:0008233 peptidase activity }\end{array}$ & $\begin{array}{l}\text { Protein kinase N1 (Pkn1) } \\
\text { Phosphodiesterase 10A (Pde10a) } \\
\text { Junction plakoglobin (Jup) } \\
\text { Protein kinase C, zeta (Prkcz) }\end{array}$ \\
\hline
\end{tabular}


A

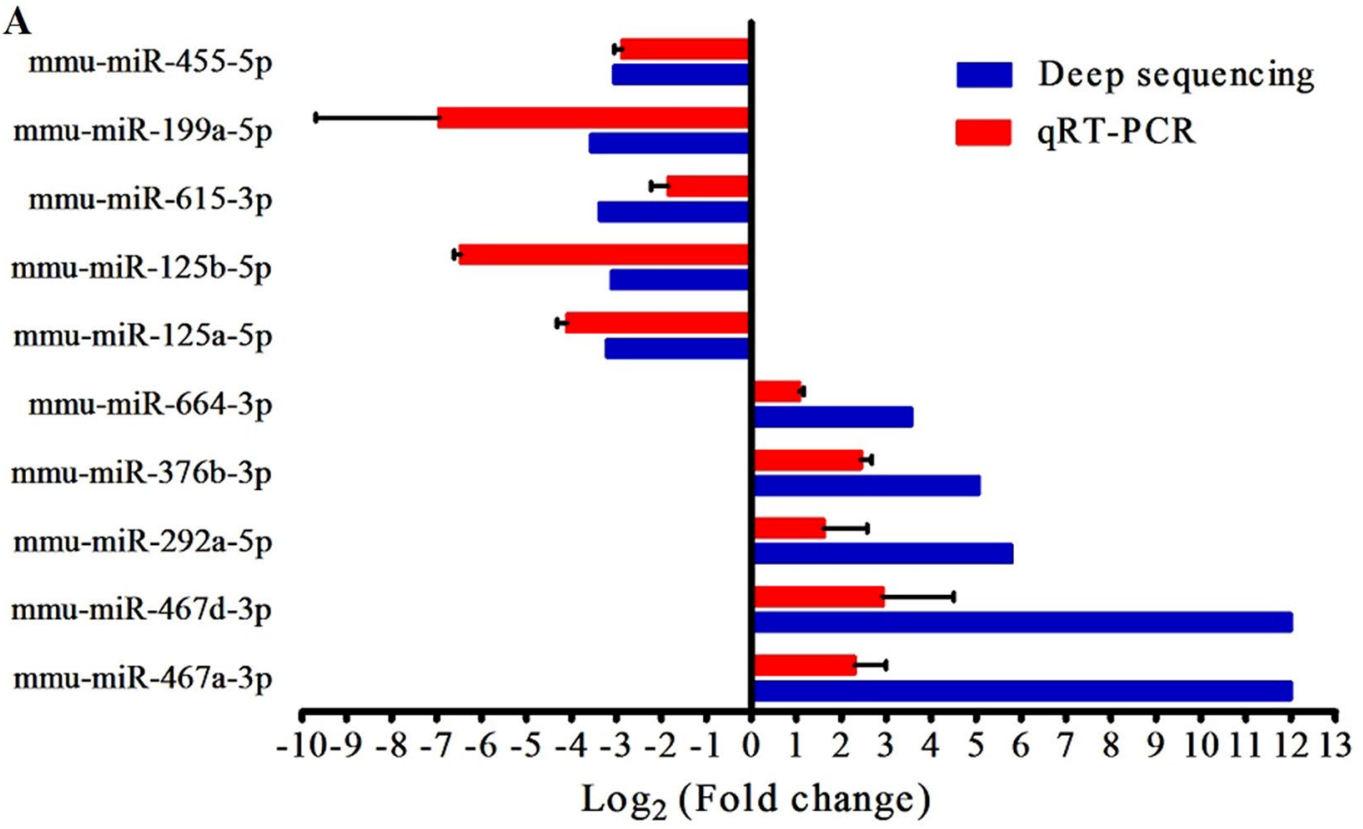

B

Uninfected Infected

mmu-miR-467a-3p

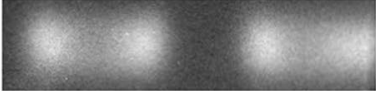

mmu-miR-125a-5p

Uninfected Infected

mmu-miR-467d-3p

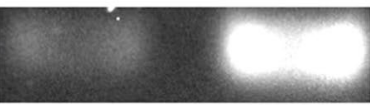

mmu-miR-125b-5p

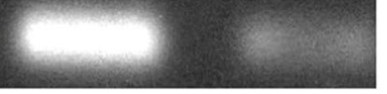

mmu-miR-292a-5p

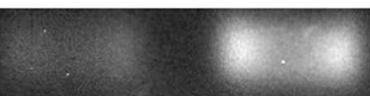

mmu-miR-615-3p

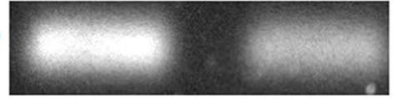

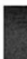

mmu-miR-376b-3p

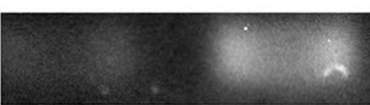

mmu-miR-664-3p

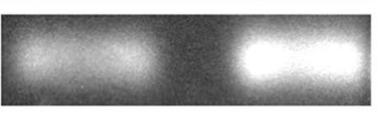

mmu-miR-199a-5p

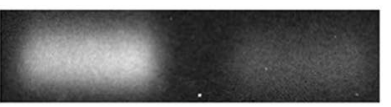

mmu-miR-455-5p

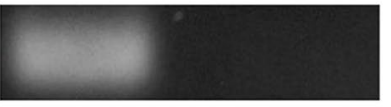

U6 snRNA

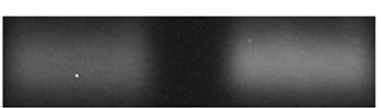

Figure 4 Verification of the ten differentially expressed mouse circulating miRNAs by qRT-PCR. The expression levels of all ten differentially expressed miRNAs, which were identified from high-throughput sequencing and bioinformatics analyses, were analysed using qRT-PCR to validate the sequencing results. A The relative expression levels by qRT-PCR of the ten miRNAs in the sera of mice infected with T. spiralis. Total RNA was isolated from infected mouse serum at $30 \mathrm{dpi}$ and subjected to qRT-PCR as described in "Materials and methods". Expression levels were normalized to the U6 snRNA levels, and relative expression values were calculated as follows: fold change $=2^{-\Delta \Delta C t}$. The final relative expression is presented as $\log _{2}$ (fold change) (mean $\pm S D$ ), which is a $\log _{2}$ transformation of the fold change. Red and blue columns indicate the results of qRT-PCR and high-throughput sequencing, respectively. B The qRT-PCR products of the ten miRNAs were confirmed by agarose gel electrophoresis.

\section{Discussion}

It is well known that circulating miRNAs of mammalian hosts are dysregulated during helminthic infections, suggesting their regulatory roles in host-parasite interactions. Previous studies have shown that Echinococcus granulosus and S. japonicum infection could alter the expression levels of host circulating miRNAs [24, 25]. To date, no studies have investigated the profile of host circulating miRNAs during infection with $T$. spiralis. It is well known that newborn larvae released by adults burst into blood, reach skeletal muscle, and invade skeletal muscle fibres. During this process, pathological 


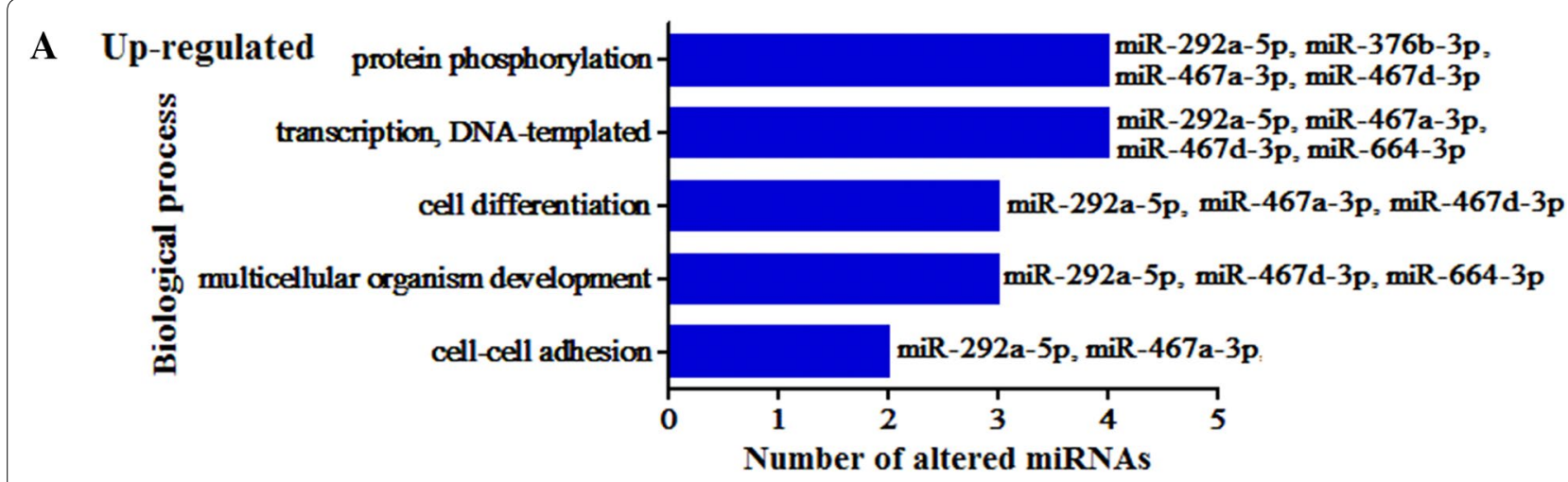

\section{B Down-regulated}

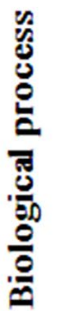

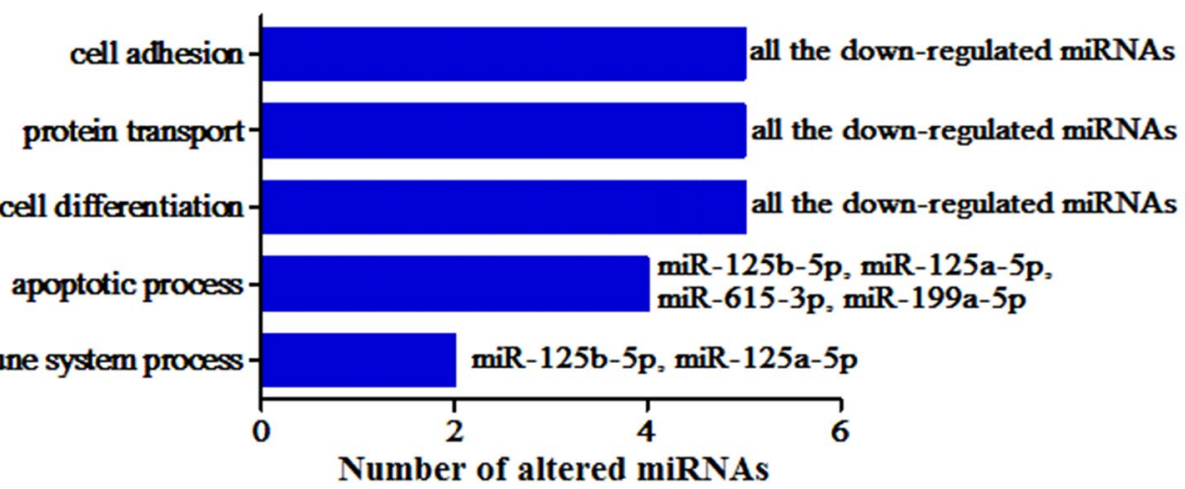

Number of altered miRNAs

Figure $5 \mathrm{GO}$ analysis of target genes of altered mouse circulating miRNAs after T. spiralis (upregulated miRNAs for A and downregulated miRNAs for B). Biological process is one of the three GO categories. A full list of GO terms of the ten altered miRNAs is shown in Additional file 7.

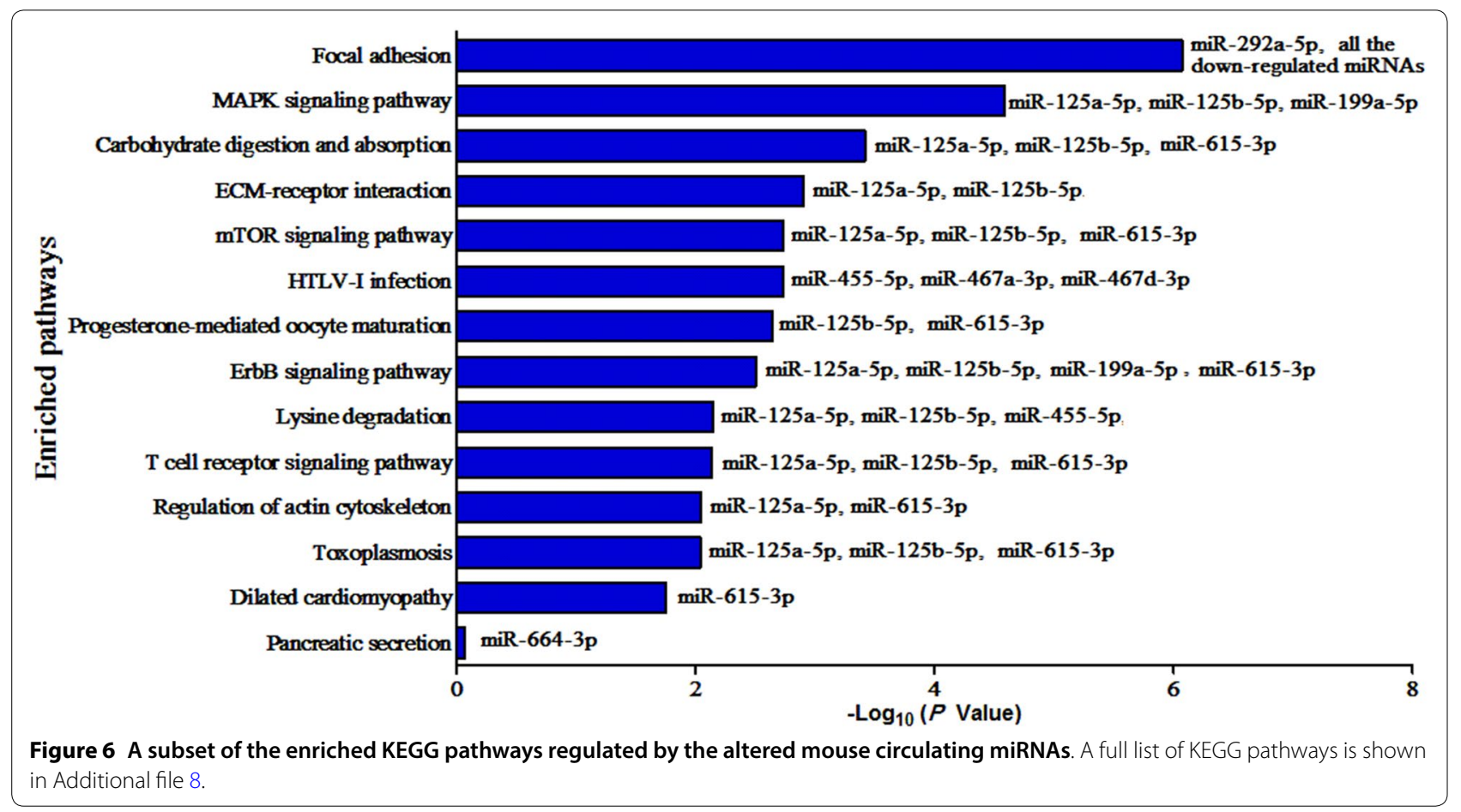




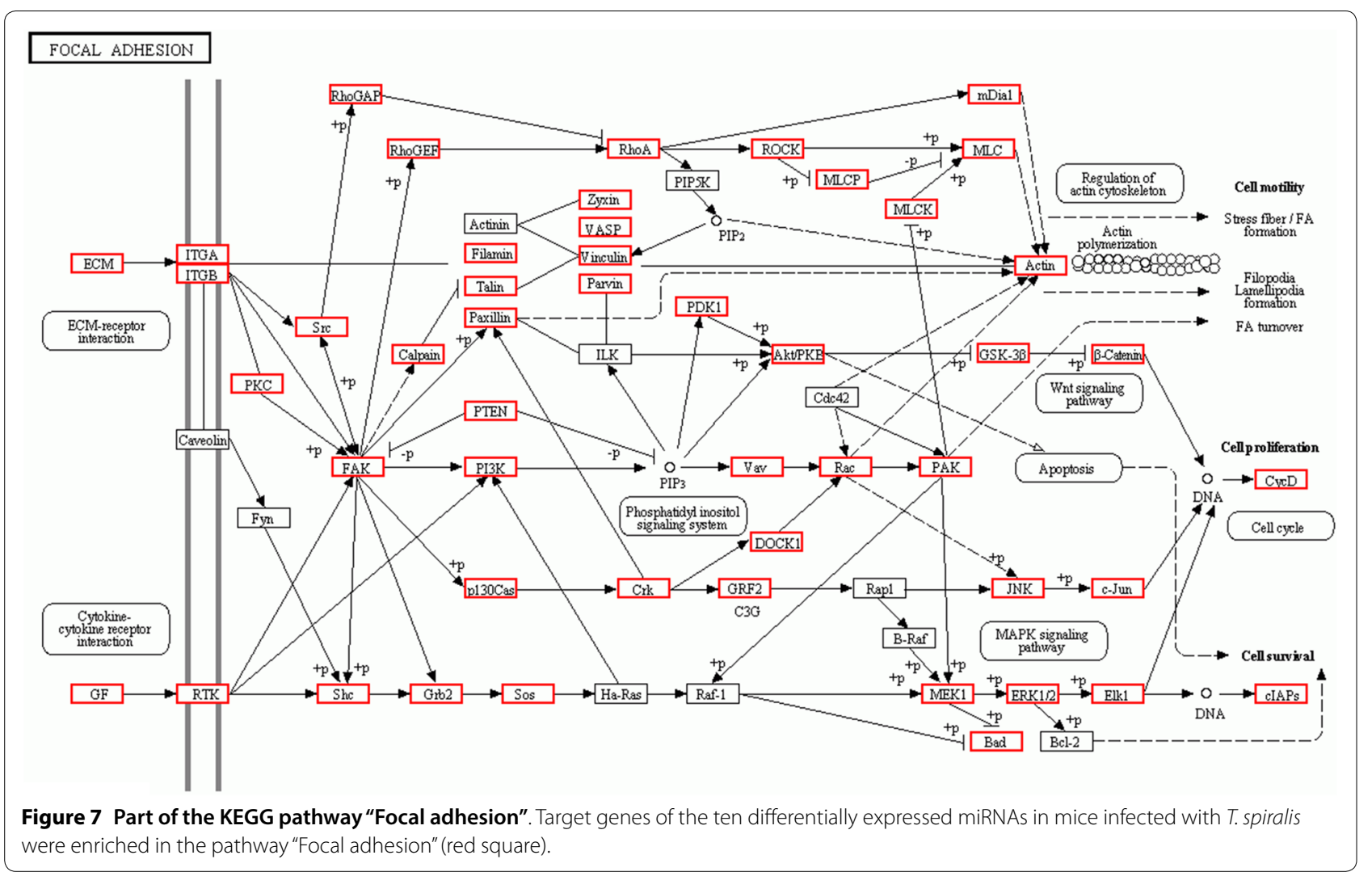

changes, such as the increase in inflammatory mediators, occur in the host serum [26]. This suggests that the host-Trichinella interaction could induce changes in host circulating miRNAs. Hence, in the present study, for the first time, mouse miRNAs in serum were identified at 30 $\mathrm{dpi}$ by high-throughput sequencing. Since the parasite at $30 \mathrm{dpi}$ is in the early ML phase and newborn larvae are still continuously released by adults, at this time point worms at different developmental stages exist simultaneously: adult worms in intestine tissues, newborn larvae in blood, and pre-encapsulated larvae and ML in muscle tissues. This means that more information on host circulating miRNAs could be acquired. In total, ten dysregulated circulating miRNAs in mice infected with $T$. spiralis at $30 \mathrm{dpi}$ were found in this study. Bioinformatic analysis indicated that these miRNAs might regulate many biological functions, such as binding, catalytic activity, and molecular transducer activity. The expression of these host circulating miRNAs was further analysed at different time points (12 and $18 \mathrm{dpi}$ ) when the larvae were in the pre-encapsulated phase and anti-T. spiralis antibodies in serum could not yet be detected [27]. Because circulating miRNAs might be potential biomarkers for trichinellosis or crucial mediators of host-Trichinella interactions, the identification of altered circulating
miRNAs in Trichinella-infected hosts will be beneficial to further understand the mechanisms of this disease and find promising novel biomarkers for trichinellosis.

To date, some functions of the altered miRNAs found in this study have been reported. They might play their roles by targeting specific genes and participating in signalling pathways. For example, miR-467a could inhibit neural differentiation and brain development by targeting Sox6 [28], might regulate the apoptosis of thymic lymphocytes by targeting Fas and Bax [29], and could be an indicator of severe malaria infection [30]. Moreover, miR-467d might be involved in the transformation of colonic epithelial cells by regulating MAPK, PI3K, and other pathways [31]. miR-376b could inhibit macrophage autophagy by directly targeting autophagy-related Atg5 [32] and could regulate the expression of the inflammatory factor IL- 6 by targeting the NF-kappa-B inhibitor zeta and STAT3 [33]. miR-664 and miR-455-5p were proven to be associated with carcinoma cell proliferation, apoptosis, and migration by targeting diverse signalling pathways $[34,35]$.

To further elucidate the functions of these altered miRNAs in trichinellosis, KEGG pathway analysis was used to identify signalling pathways of their predicted target genes. The results showed that "Focal adhesion" and "MAPK signaling pathway" were two of the most 


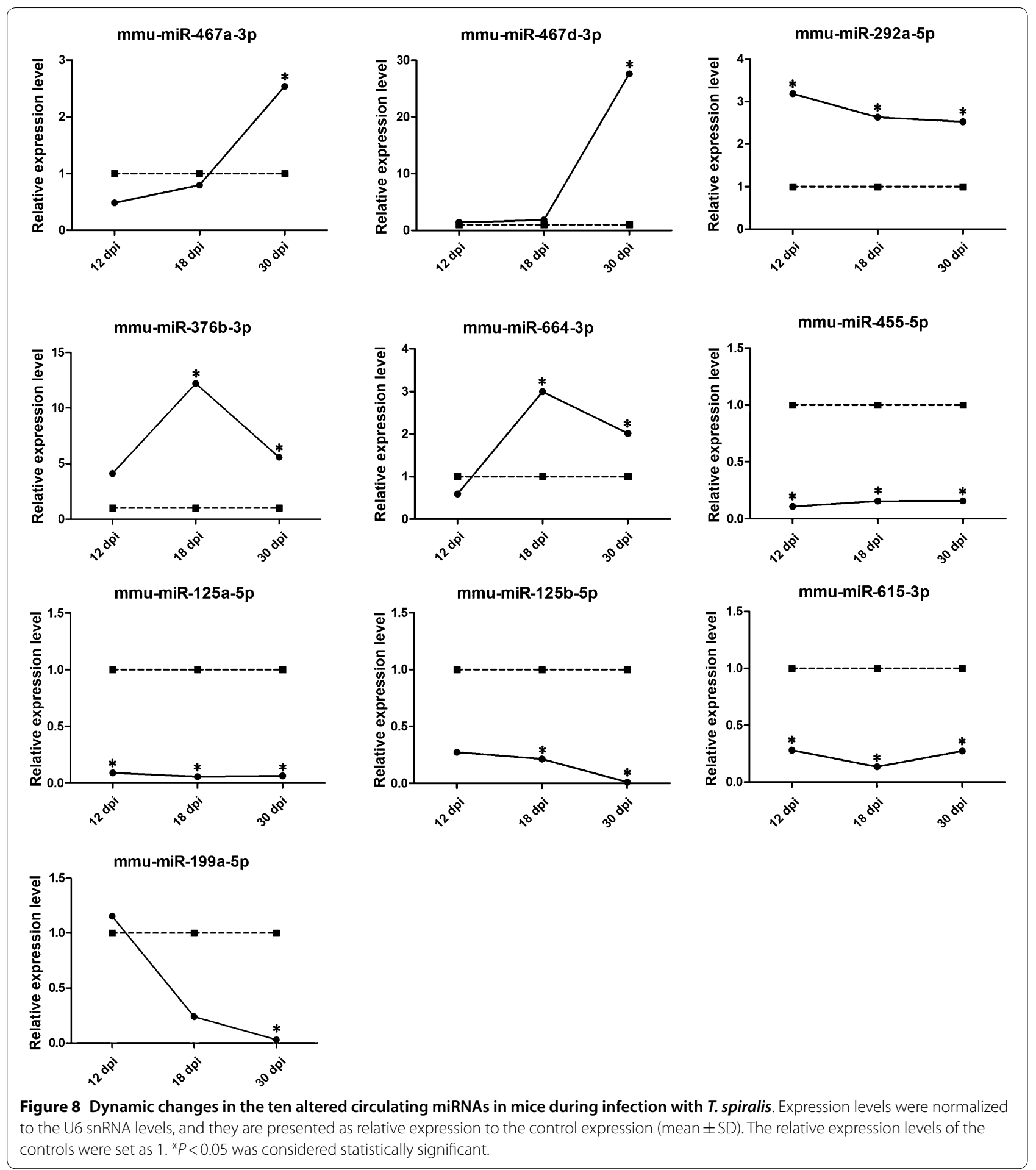

enriched pathways. The Focal adhesion pathway has a wide range of biological functions, including the immune response and barrier function. Focal adhesion, acting as a cellular sensor and regulator, could anchor cells to the extracellular matrix and directly assemble the prestressed actin cytoskeleton [36]. Previous studies have shown that the inhibition of focal adhesion formation facilitates the hypermotility of monocytes infected with Toxoplasma gondii (T. gondii) [37], and the dysregulation of focal adhesion kinase facilitates the transmigration of $T$. 
gondii across polarized endothelial cell monolayers [38]. Moreover, the loss of focal adhesion kinase in endothelial cells could enhance cell attachment and cell-cell contacts [39]. Focal adhesion could also promote the migration of neutrophils from blood vessels to infection sites by participating in endothelial conformational changes [40]. In the present study, an enrichment of the Focal adhesion pathway was found in T. spiralis infection, and GO analysis of the predicted target genes identified the GO term "cytoskeletal protein binding and endomembrane system". These results suggest that the expression of genes related to focal adhesion might be altered in hosts infected with T. spiralis, resulting in changes in focal adhesion and tight junction formation of epithelial monolayers, which might be beneficial for host defences against $T$. spiralis infection. Among the altered miRNAs, mmu-miR-125a-5p and mmu-miR-615-3p might be involved in the Focal adhesion pathway by targeting Pik3cd, laminin or other genes.

The mitogen-activated protein kinase (MAPK) pathway, which includes p38, extracellular signal-related kinase (ERK), and Jun amino-terminal kinase (JNK1/2/3), plays an important role in cell proliferation, differentiation, migration, senescence, and apoptosis [41]. In addition, the MAPK signalling pathway also participates in innate and acquired immune responses during parasitic infection. For example, macrophages can produce IL-33 upon activation of the MAPK signalling pathway, and IL-33 can facilitate the Th2 immune response by inducing the production of proinflammatory factors and Th2-associated cytokines and activating lymphocytes, eosinophils and mastocytes [42]. Previous studies have proven the functions of IL-33 against infection with various parasites, including Schistosoma japonica, Angiostrongylus, Trichuris muris, and hookworm [43, 44]. In addition, the MAPK pathway could also downregulate proinflammatory factors by targeting miR-664 in the ileum [45]. In this study, target genes (such as MAPK1) of miR-664 were enriched in the MAPK pathway, suggesting that the alteration of miR-664 would regulate proinflammatory factors through the MAPK pathway in hosts infected with T. spiralis. These findings were consistent with the enriched GO term "activation of MAPK activity". Moreover, miR-376 is a mediator of the MAPK pathway [46], and miR-125 could decrease the phosphorylation of MAPK pathway component, including ERK, p38, and JNK [47]. This study showed that mmu-miR376b-3p, mmu-miR-664-3p, mmu-miR-125b-5p, and $\mathrm{mmu}-\mathrm{miR}-125 \mathrm{a}-5 \mathrm{p}$ were involved in the MAPK pathway, supporting the hypothesis that the MAPK pathway might participate in the dysregulation of pathological responses during T. spiralis infection.
Host immune responses to T. spiralis infection mainly occur in the intestinal phase and muscular phase [48]. Invasion by ML can result in host muscle damage and an intensive inflammatory response, a complex T-helper type-2 (Th2) immune response. The Th2 cytokine IL-10 has been proven to be an important regulator during host-parasite interactions. It can limit the inflammatory responses and protect the host against injury during the acute phase of muscle infection while inducing the Th2 response to protect the mature, infectious parasite during chronic infection [49]. The production of IL-10 requires the phosphorylation of MAPK, which was one of the most enriched pathways in this study [50]. Among the ten miRNAs, the downregulated mmu-miR-125a-5p, mmu-miR-125b-5p, and mmu-miR-615-3p were enriched in the MAPK pathway by targeting the tumour necrosis factor receptor superfamily (Tnfrsf1a), tumour necrosis factor (Tnf), or dual specificity phosphatase (Dusp 4, 6, 7, and 8). In addition, mmu-miR-125a-5p, mmu-miR-125b-5p, and mmu-miR-199a-5p were found to target IL-10 receptor alpha (IL10RA), suggesting that these miRNAs might affect the functions of IL-10 to then regulate the $T h 2$ immune response during $T$. spiralis infection.

T. spiralis infection results in alterations of small intestinal physiology, which includes changes in mucus production and intestinal motility, and initiates immune responses mediated by cytokines released from Th2 cells [51]. A potent Th2-type immune response could induce intestinal muscle hypercontractility and worm expulsion during the intestinal phase. Attenuated muscle contractility and reduced parasite expulsion were found in athymic mice infected with $T$. spiralis [52], suggesting that the host $\mathrm{T}$ cell-mediated immune response plays a leading role in parasite expulsion. Th2-type cytokines, such as IL-4 and IL-13, can promote T. spiralis expulsion by $\mathrm{T}$ cells and mast cells [53]. Moreover, Th1 responses are also involved in immune regulation during parasite infection and suppress effective anti-parasite immunity. Th1-type cytokines, such as IL-12 and IFN- $\gamma$, can inhibit Th2-type immune responses by inhibiting IL-4 production [54]. In addition, the CD40-CD40 ligand interaction influences the production of monocyte chemoattractant protein-1 (MCP-1), whose deficiency results in a shift from Th2 to Th1 immune responses [55, 56]. In this study, the downregulated mmu-miR-615-3p and mmumiR-455-5p targeted CD40, CD40 ligand (CD40LG), IFN- $\gamma$ receptor 2 (IFNGR2), or interleukin 12B (IL-12B). It could be speculated that these downregulated host miRNAs might regulate the intensity of the Th2 immune response induced by $T$. spiralis infection and promote parasite expulsion. 
Mucins, the protective barrier of the underlying epithelium, play a protective role against infection by trapping parasites and inhibiting parasite motility and feeding capacity. The ingestion of mucus by the worms may have a deleterious effects on them. In the small intestine, excess production of mucus by hyperplastic goblet cells has been found in infections with multiple parasites [51]. In addition, mucin genes were found to be upregulated during parasite infections, such as $T$. spiralis infection [57]. Cytokines, especially Th2-type cytokines (IL-4, IL-9, and IL-13), can regulate mucin production. They can induce goblet cell hyperplasia and mucin production by Stat6 pathways during $T$. spiralis infection. Otherwise, laminins are the major structural component of the basement membrane, which is a meshwork of proteins separating the epithelium from connective tissue. Laminin can enhance myotube formation by modulating type I collagen films after damage to skeletal muscle [58]. In the present study, functional analyses showed that all five downregulated miRNAs might target laminin, suggesting that they could regulate the expression of laminin and promote repair of host skeletal muscle injury caused by T. spiralis infection.

Since the profiles of circulating miRNAs could be changed in host serum during parasite infection, characterizing these profiles would be helpful in understanding the roles of miRNAs in the regulation of molecular networks related to infection. Therefore, the roles of circulating miRNAs (especially upregulated miRNAs) as potential biomarkers of parasitic diseases have become increasingly evident [29]. This work further investigated the expression levels of the ten altered circulating miRNAs at 12,18 , and $30 \mathrm{dpi}$. The results showed that among the 5 upregulated miRNAs, mmu-miR-467a-3p and mmu-miR-467d-3p expression reached a peak at $30 \mathrm{dpi}$, while the expression of mmu-miR-376b-3p and mmu-miR-664-3p increased significantly at $18 \mathrm{dpi}$ and then decreased at $30 \mathrm{dpi}$. In addition, the expression of mmu-miR-292a-5p gradually decreased from 12 to $30 \mathrm{dpi}$. The variation of individual miRNAs at different time points might be associated with the infection phases of T. spiralis; hence, detailed detection of the kinetics of these altered circulating miRNAs could reveal novel candidate biomarkers for trichinellosis, especially in the early phase of infection. Certainly, the clinical potential of these altered miRNAs needs to be verified in further studies.

In conclusion, this study provides the profiles of differentially expressed circulating host miRNAs during $T$. spiralis infection. GO and KEGG pathway enrichment analyses were performed for a functional analysis of the target genes of the ten altered miRNAs. In particular, the pathways "Focal adhesion" and "MAPK signaling pathway" were enriched during T. spiralis infection and might be important mediators in the host-Trichinella interactions. This paper will be helpful in understanding the mechanisms involved in Trichinella parasitism and provide promising serum biomarkers for trichinellosis.

\section{Supplementary information}

Supplementary information accompanies this paper at https://doi. org/10.1186/s13567-020-00758-0.

Additional file 1. Overview of small RNA-seq data of all libraries Additional file 2. Distribution of the different types of small RNA. Additional file 3. The sequences of known miRNAs in T. spiralis miRNA libraries.

Additional file 4. The sequences of novel miRNAs in T. spiralis miRNA libraries.

Additional file 5. The mean expression levels of miRNAs in the sera of the infected and uninfected mice.

Additional file 6 . The predicted target genes of each altered circulating miRNA in mice infected with $T$. spiralis.

Additional file 7. GO analysis of target genes of each altered circulating miRNA in mice infected with $T$. spiralis.

Additional file 8. KEGG analysis of target genes of each altered circulating miRNA in mice infected with $T$. spiralis.

\section{Acknowledgements}

The authors would like to thank Dr Shan Shan Li from CapitalBio Technology Company (Beijing) for her technical assistance.

\section{Authors' contributions}

Study design and manuscript writing: LM, HJR, and XHM; sample collection and analysis: XHM, RYP, and YL. All authors read and approved the final manuscript.

\section{Funding}

This work was supported by the National Natural Science Foundation of China (No. 81401682), the Programs for Science and Technology Development of Henan Province (172102310649), and the Key Scientific Research Program of Higher Education of Henan Province (19B310006).

Availability of data and materials

The datasets used and/or analysed during the current study are available from the corresponding author upon reasonable request.

\section{Competing interests}

The authors declare that they have no competing interests.

\section{Author details}

${ }^{1}$ Department of Clinical Laboratory, The First Affiliated Hospital of Zhengzhou University, Zhengzhou 450052, China. ${ }^{2}$ Key Clinical Laboratory of Henan Province, Zhengzhou 450052, China.

Received: 15 August 2019 Accepted: 15 January 2020

Published online: 11 March 2020

\section{References}

1. Rostami A, Gamble HR, Dupouy-Camet J, Khazan H, Bruschi F (2017) Meat sources of infection for outbreaks of human trichinellosis. Food Microbiol 64:65-71 
2. Ren HJ, Cui J, Yang W, Liu RD, Wang ZQ (2013) Identification of differentially expressed genes of Trichinella spiralis larvae after exposure to host intestine milieu. PLoS One 8:e67570

3. Bushati N, Cohen SM (2007) microRNA functions. Annu Rev Cell Dev 23:175-205

4. Nakato G, Hase K, Sato T, Kimura S, Sakakibara S, Sugiyama M, Obata Y, Hanazato M, Iwanaga T, Ohno H (2016) Epithelium-intrinsic MicroRNAs contribute to mucosal immune homeostasis by promoting M-cell maturation. PLoS One 11:e0150379

5. Stephenson LS, Latham MC, Ottesen EA (2000) Malnutrition and parasitic helminth infections. Parasitology 121(Supp 1):S23-S38

6. Skalsky RL, Cullen BR (2010) Viruses, microRNAs, and host interactions. Annu Rev Microbiol 64:123-141

7. Hoy AM, Lundie RJ, Ivens A, Quintana JF, Nausch N, Forster T, Jones F, Kabatereine NB, Dunne DW, Mutapi F, Macdonald AS, Buck AH (2014) Parasite-derived microRNAs in host serum as novel biomarkers of helminth infection. PLoS Negl Trop Dis 8:e2701

8. Cheng G, Luo R, Hu C, Cao J, Jin Y (2013) Deep sequencing-based identification of pathogen-specific microRNAs in the plasma of rabbits infected with Schistosoma japonicum. Parasitology 140:1751-1761

9. He X, Sai X, Chen C, Zhang Y, Xu X, Zhang D, Pan W (2013) Host serum miR-223 is a potential new biomarker for Schistosoma japonicum infection and the response to chemotherapy. Parasite Vectors 6:272

10. Chen MX, Ai L, Xu MJ, Chen SH, Zhang YN, Guo J, Cai YC, Tian LG, Zhang LL, Zhu XQ, Chen JX (2011) Identification and characterization of microRNAs in Trichinella spiralis by comparison with Brugia malayi and Caenorhabditis elegans. Parasitol Res 109:553-558

11. Padmashree D, Ramachandraswamy N (2016) Identification and characterization of conserved miRNAs with its targets mRNA in Trichinella spiralis. Bioinformation 12:279-284

12. Long SR, Wang ZQ, Jiang P, Liu RD, Qi X, Liu P, Ren HJ, Shi HN, Cui J (2015) Characterization and functional analysis of Trichinella spiralis Nudix hydrolase. Exp Parasitol 159:264-273

13. GenBank database. https://www.ncbi.nlm.nih.gov/genbank/. Accessed 25 Dec 2018

14. Rfam. http://rfam.xfam.org/. Accessed 25 Dec 2018

15. miRBase v21.0 database. http://www.mirbase.org/. Accessed 25 Dec 2018

16. Friedlander MR, Mackowiak SD, Li N, Chen W, Rajewsky N (2012) miRDeep2 accurately identifies known and hundreds of novel microRNA genes in seven animal clades. Nucleic Acids Res 40:37-52

17. Zhou L, Chen J, Li Z, Li X, Hu X, Huang Y, Zhao X, Liang C, Wang Y, Sun L, Shi M, Xu X, Shen F, Chen M, Han Z, Peng Z, Zhai Q, Chen J, Zhang Z, Yang R, Ye J, Guan Z, Yang H, Gui Y, Wang J, Cai Z, Zhang X (2010) Integrated profiling of microRNAs and mRNAs: microRNAs located on Xq27.3 associate with clear cell renal cell carcinoma. PLoS One 5:e15224

18. Livak KJ, Schmittgen TD (2001) Analysis of relative gene expression data using real-time quantitative PCR and the 2(-Delta Delta C(T)) Method. Methods 25:402-408

19. Lewis BP, Shih $\mathrm{H}$, Jones-Rhoades MW, Bartel DP, Burge CB (2003) Prediction of mammalian microRNA targets. Cell 115:787-798

20. Enright AJ, John B, Gaul U, Tuschl T, Sander C, Marks DS (2003) MicroRNA targets in Drosophila. Genome Biol 5:R1

21. Cheng C, Bhardwaj N, Gerstein M (2009) The relationship between the evolution of microRNA targets and the length of their UTRs. BMC Genomics 10:431

22. Kruger J, Rehmsmeier M (2006) RNAhybrid: microRNA target prediction easy, fast and flexible. Nucleic Acids Res 34:W451-454

23. Dennis G, Sherman BT, Hosack DA, Yang J, Gao W, Lane HC, Lempicki RA (2003) DAVID: database for annotation, visualization, and integrated discovery. Genome Biol 4:P3

24. Guo X, Zheng $Y$ (2017) Expression profiling of circulating miRNAs in mouse serum in response to Echinococcus multilocularis infection. Parasitology 144:1079-1087

25. Zhu L, Dao J, Du X, Li H, Lu K, Liu J, Cheng G (2015) Altered levels of circulating miRNAs are associated Schistosoma japonicum infection in mice. Parasit Vectors 8:196

26. Farid AS, Fath EM, Mido S, Nonaka N, Horii Y (2019) Hepatoprotective immune response during Trichinella spiralis infection in mice. J Vet Med Sci 81:169-176

27. Sun GG, Song YY, Jiang P, Ren HN, Yan SW, Han Y, Liu RD, Zhang X, Wang ZQ, Cui J (2018) Characterization of a Trichinella spiralis putative serine protease. Study of its potential as sero-diagnostic tool. PLoS Negl Trop Dis 12:e0006485

28. Zhang L, Xue Z, Yan J, Wang J, Liu Q, Jiang H (2019) LncRNA Riken-201 and Riken-203 modulates neural development by regulating the Sox6 through sequestering miRNAs. Cell Prolif 52:e12573

29. Gao F, Chen S, Sun M, Mitchel RE, Li B, Chu Z, Cai J, Liu C (2015) MiR-467a is upregulated in radiation-induced mouse thymic lymphomas and regulates apoptosis by targeting Fas and Bax. Int J Biol Sci 11:109-121

30. Cohen A, Zinger A, Tiberti N, Grau GER, Combes V (2018) Differential plasma microvesicle and brain profiles of microRNA in experimental cerebral malaria. Malar J 17:192

31. Necela BM, Carr JM, Asmann YW, Thompson EA (2011) Differential expression of microRNAs in tumors from chronically inflamed or genetic (APC(Min/+)) models of colon cancer. PLoS One 6:e18501

32. Yang $S$, Abdulla R, Lu C, Zhang L (2018) Inhibition of microRNA-376b protects against renal interstitial fibrosis via inducing macrophage autophagy by upregulating Atg 5 in mice with chronic kidney disease. Kidney Blood Press Res 43:1749-1764

33. Lu S, Jiao H, Xu J, Zheng Y, Sun Y, Chen H (2015) Downregulation of IL6 targeted MiR-376b may contribute to a positive IL6 feedback loop during early liver regeneration in mice. Cell Physiol Biochem 37:233-242

34. Wang X, Zhou Z, Zhang T, Wang M, Xu R, Qin S, Zhang S (2019) Overexpression of miR-664 is associated with poor overall survival and accelerates cell proliferation, migration and invasion in hepatocellular carcinoma. Onco Targets Ther 12:2373-2381

35. Xing Q, Xie H, Zhu B, Sun Z, Huang Y (2019) MiR-455-5p suppresses the progression of prostate cancer by targeting CCR5. Biomed Res Int 2019:6394784

36. Mead TJ, Du Y, Nelson CM, Gueye NA, Drazba J, Dancevic CM, Vankemmelbeke M, Buttle DJ, Apte SS (2018) ADAMTS9-regulated pericellular matrix dynamics governs focal adhesion-dependent smooth muscle differentiation. Cell Rep 23:485-498

37. Cook JH, Ueno N, Lodoen MB (2018) Toxoplasma gondii disrupts betal integrin signaling and focal adhesion formation during monocyte hypermotility. J Biol Chem 293:3374-3385

38. Ross EC, Olivera GC, Barragan A (2019) Dysregulation of focal adhesion kinase upon Toxoplasma gondii infection facilitates parasite translocation across polarised primary brain endothelial cell monolayers. Cell Microbiol 21:e13048

39. Arnold KM, Goeckeler ZM, Wysolmerski RB (2013) Loss of focal adhesion kinase enhances endothelial barrier function and increases focal adhesions. Microcirculation 20:637-649

40. Parsons SA, Sharma R, Roccamatisi DL, Zhang H, Petri B, Kubes P, Colarusso P, Patel KD (2012) Endothelial paxillin and focal adhesion kinase (FAK) play a critical role in neutrophil transmigration. Eur J Immunol 42:436-446

41. Sun Y, Liu WZ, Liu T, Feng X, Yang N, Zhou HF (2015) Signaling pathway of MAPK/ERK in cell proliferation, differentiation, migration, senescence and apoptosis. J Recept Signal Transduct Res 35:600-604

42. Moussion C, Ortega N, Girard JP (2008) The IL-1-like cytokine IL-33 is constitutively expressed in the nucleus of endothelial cells and epithelial cells in vivo: a novel'alarmin'? PLoS One 3:e3331

43. Wills-Karp M, Rani R, Dienger K, Lewkowich I, Fox JG, Perkins C, Lewis L, Finkelman FD, Smith DE, Bryce PJ, Kurt-Jones EA, Wang TC, Sivaprasad U, Hershey GK, Herbert DR (2012) Trefoil factor 2 rapidly induces interleukin 33 to promote type 2 immunity during allergic asthma and hookworm infection. J Exp Med 209:607-622

44. Humphreys NE, Xu D, Hepworth MR, Liew FY, Grencis RK (2008) IL-33, a potent inducer of adaptive immunity to intestinal nematodes. J Immunol 180:2443-2449

45. Zhang Q, Xiao X, Li M, Li W, Yu M, Zhang H, Wang Z, Xiang H (2013) Acarbose reduces blood glucose by activating miR-10a-5p and miR-664 in diabetic rats. PLoS One 8:e79697

46. Bakhshandeh B, Soleimani M, Paylakhi SH, Ghaemi N (2012) A microRNA signature associated with chondrogenic lineage commitment. J Genet 91:171-182

47. Wu QB, Chen J, Zhu JW, Yin X, You HY, Lin YR, Zhu HQ (2018) MicroRNA125 inhibits RKO colorectal cancer cell growth by targeting VEGF. Int J Mol Med 42:665-673

48. Ilic N, Gruden-Movsesijan A, Sofronic-Milosavljevic LJ (2012) Trichinella spiralis: shaping the immune response. Immunol Res 52:111-119 
49. Fabre MV, Beiting DP, Bliss SK, Appleton JA (2009) Immunity to Trichinella spiralis muscle infection. Vet Parasitol 159:245-248

50. Carneiro-Santos P, Alves-Oliveira LF, Correa-Oliveira R, Hagan P (2002) P38 mitogen-activated protein kinase influence on the production of IL-10 in human schistosomiasis mansoni. Parasite Immunol 24:493-497

51. Khan WI, Collins SM (2004) Immune-mediated alteration in gut physiology and its role in host defence in nematode infection. Parasite Immunol 26:319-326

52. Vallance BA, Croitoru K, Collins SM (1998) T lymphocyte-dependent and -independent intestinal smooth muscle dysfunction in the T. spiralisinfected mouse. Am J Physiol 275:G1157-1165

53. Finkelman FD, Shea-Donohue T, Morris SC, Gildea L, Strait R, Madden KB, Schopf L, Urban JF Jr (2004) Interleukin-4- and interleukin-13-mediated host protection against intestinal nematode parasites. Immunol Rev 201:139-155

54. Gately MK, Renzetti LM, Magram J, Stern AS, Adorini L, Gubler U, Presky DH (1998) The interleukin-12/interleukin-12-receptor system: role in normal and pathologic immune responses. Annu Rev Immunol 16:495-52

55. Khan WI, Motomura Y, Blennerhassett PA, Kanbayashi H, Varghese AK, El-Sharkawy RT, Gauldie J, Collins SM (2005) Disruption of CD40-CD40 ligand pathway inhibits the development of intestinal muscle hypercontractility and protective immunity in nematode infection. Am J Physiol Gastrointest Liver Physiol 288:G15-22

56. deSchoolmeester ML, Little MC, Rollins BJ, Else KJ (2003) Absence of CC chemokine ligand 2 results in an altered Th1/Th2 cytokine balance and failure to expel Trichuris muris infection. J Immunol 170:4693-4700

57. Shekels LL, Anway RE, Lin J, Kennedy MW, Garside P, Lawrence CE, Ho SB (2001) Coordinated Muc2 and Muc3 mucin gene expression in Trichinella spiralis infection in wild-type and cytokine-deficient mice. Dig Dis Sci 46:1757-1764

58. Grefte S, Adjobo-Hermans MJW, Versteeg EMM, Koopman WJH, Daamen WF (2016) Impaired primary mouse myotube formation on crosslinked type I collagen films is enhanced by laminin and entactin. Acta Biomater $30: 265-276$

\section{Publisher's Note}

Springer Nature remains neutral with regard to jurisdictional claims in published maps and institutional affiliations.
Ready to submit your research? Choose BMC and benefit from:

- fast, convenient online submission

- thorough peer review by experienced researchers in your field

- rapid publication on acceptance

- support for research data, including large and complex data types

- gold Open Access which fosters wider collaboration and increased citations

- maximum visibility for your research: over $100 \mathrm{M}$ website views per year

At BMC, research is always in progress.

Learn more biomedcentral.com/submissions 